\title{
Variation in the magnitude of black-white differences in stroke mortality by community occupational structure
}

\author{
Michele Casper, Steve Wing, David Strogatz
}

\begin{abstract}
Study objective-The aim was to examine the patterns of black-white differences in stroke mortality across communities with varying levels of occupational structure in the southern region of the United States

Design-Annual age adjusted race-sex specific rates for stroke mortality were calculated for the years 1979-1981 and related to socioeconomic conditions.

Setting-The study involved 211 state economic areas comprising the southern region of the USA.

Study population-Data on stroke mortality for black and white men and women between the ages of 35 and 74 years living in the study area were acquired from the National Center for Health Statistics.

Measurements and main resultsOccupational structure was measured as the proportion of white collar workers in each state economic area, and is an indicator of the employment opportunities and related social and economic resources of a community. Stratified analyses and linear regression modelling indicate that communities of lower occupational structure have (a) higher levels of stroke mortality for all four race-sex groups $(p<0.05)$ and (b) larger racial inequalities in stroke mortality $(p<0.01)$. For men and women, the excess stroke mortality among blacks compared to whites is larger in communities of lower occupational structure.
\end{abstract}

Conclusions-Consideration of occupational structure and related patterns of economic development is crucial for understanding the distribution of stroke mortality within and between racial groups, as well as for planning effective public health interventions. The larger racial inequalities in communities of lower occupational structure in the south suggest that aspects of the black experience which are conducive to high rates of stroke mortality are exacerbated in those communities. Public health interventions to reduce the racial and social inequalities in stroke mortality should recognise the social context within which nutritional, occupational, medical care, and environmental determinants of stroke are distributed.

The well documented pattern of higher hypertension related morbidity and mortality among blacks than among whites in the United States has led researchers to investigate the racial differentials. One line of inquiry has examined the relationship between indices of community socioeconomic structure and hypertension related morbidity and mortality for blacks and whites. ${ }^{1-4}$ This perspective addresses the concept that macro level social and economic conditions influence the distribution of risk factors for hypertension related morbidity and mortality, and furthermore that blacks and whites may be differentially affected. However, the previous studies were not able to make direct comparisons between races because they employed race specific indices of socioeconomic structure, or compared blacks and whites from different communities. In order to understand better how social and economic forces (such as development and underdevelopment) may exacerbate or reduce racial inequalities in health, it is important to assess qualities of the socioeconomic structure which apply to both blacks and whites. In this study we examine the patterns of black-white differentials in stroke mortality among communities in the southern region of the United States which are categorised according to the overall structure instead of the race specific occupational structure.

The occupational structure of a community refers to the employment opportunities which reflect a community's placement in the national and world economy as well as its social and economic resources. The quantity and quality of such resources may affect blood pressure levels and risk of stroke through mechanisms such as diet, ${ }^{5-8}$ cigarette smoking, ${ }^{9}$ job related stress, ${ }^{10-12}$ social cohesion, ${ }^{13-15}$ economic pressures, ${ }^{16-18}$ and medical care. ${ }^{19-21}$ Hence, occupational structure is viewed here as reflecting the context within which the prevalence of risk factors for stroke are determined.

Communities may differ not only by level of social and economic resources, but also in the extent to which these resources are shared by all groups within the community. Varying racial differences in stroke mortality across levels of occupational structure may reflect the uneven dissemination of resources within poor versus more affluent communities. As an initial step in investigating this hypothesis, this study examines the pattern of racial differentials in stroke mortality across categories of occupational structure.

\section{Methods}

State economic areas are the units of analysis for this study. State economic areas were defined by 
the Bureau of the Census based upon size and composition of the population, along with the amount and type of economic activity. ${ }^{22}$ A state economic area can be either a single metropolitan county or an aggregation of non-metropolitan counties which follow county and state boundaries.

We restricted this study to the 211 state economic areas in the southern region of the United States (as defined by the Bureau of the Census). This region has consistently experienced the highest rates of stroke mortality in the United States, and a recent study showed evidence of substantial geographical variation in stroke mortality within the south. ${ }^{23}$ The recent pattern of economic development within the south, characterised by the continued underdevelopment of some areas, which remain dependent upon labour intensive low wage industries, while other areas have experienced economic growth, ${ }^{24-26}$ also provided the rationale for restricting this study to the south.

Annual age adjusted race-sex specific rates for stroke mortality among people aged $35-74$ years were calculated for each state economic area during 1979-1981. The stroke mortality data (9th revision ICD codes 430-438) were acquired from the National Center for Health Statistics, and the population counts were obtained from the Bureau of Census. The rates were directly age adjusted to the 1970 US population. In order to increase the stability of the rates, three year population weighted average rates were calculated for each race-sex specific group. The weights were the annual proportion of the total race-sex specific population, ages 35-74 years, in each state economic area for the years 1979-1981.

The occupational structure of each state economic area was represented by the proportion of the civilian labour force employed in white collar occupations in 1980. In order to reflect the occupational structure of the shared environment, we did not calculate race specific percentages of white collar workers. White collar workers include "(a) professional, technical and kindred workers, managers and administrators except farms, and (b) sales and clerical workers". These

Table I Descriptive statistics of occupational structure and stroke mortality rates across the state economics areas in the southern region of the United States

\begin{tabular}{|c|c|c|c|c|c|c|}
\hline Variable & $10 \%$ & Mean & Median & $90^{\circ} \%$ & $\begin{array}{l}90^{\circ}{ }^{\circ-10^{\circ}} \% \\
\text { Range }\end{array}$ & $\begin{array}{l}90^{\circ} / 10^{\circ} \% \\
\text { Inter } \\
\text { decile } \\
\text { ratio }\end{array}$ \\
\hline $\begin{array}{l}\text { Occupational structure (percent } \\
\text { white collar workers) } \\
\text { Stroke mortality (rate per } 100 \text { 000) }\end{array}$ & $37 \cdot 0$ & 46.9 & $45 \cdot 1$ & 59.6 & $22 \cdot 6$ & 1.6 \\
\hline $\begin{array}{l}\text { Black men } \\
\text { Black women } \\
\text { White men } \\
\text { White women }\end{array}$ & $\begin{array}{l}89.1 \\
72.9 \\
53 \cdot 8 \\
39.9\end{array}$ & $\begin{array}{r}181 \cdot 1 \\
128 \cdot 2 \\
71 \cdot 2 \\
51 \cdot 5\end{array}$ & $\begin{array}{r}177 \cdot 4 \\
125 \cdot 9 \\
71 \cdot 2 \\
50.9\end{array}$ & $\begin{array}{r}264.6 \\
188.8 \\
88.4 \\
63.0\end{array}$ & $\begin{array}{r}175 \cdot 5 \\
115.9 \\
34 \cdot 6\end{array}$ & $\begin{array}{l}3 \cdot 0 \\
2 \cdot 6 \\
1 \cdot 6\end{array}$ \\
\hline White women & 39.9 & 51.5 & 50.9 & 63.0 & $23 \cdot 1$ & $1 \cdot 6$ \\
\hline
\end{tabular}

Table II Distribution of state economic areas (SEAs) and race-sex specific personyears by category of occupational structure

\begin{tabular}{lrrrrrr}
\hline & \multicolumn{3}{c}{ Occupational structure } & & & \\
\cline { 2 - 7 } & 1 (low) & 2 & \multicolumn{1}{c}{3} & 4 & 5 (high) \\
\hline $\begin{array}{l}\text { Range of \% white collar workers } \\
\text { No of SEAs (\%) }\end{array}$ & 540 & $41-48$ & $49-56$ & $57-64$ & $>64$ \\
Person-years & & $76(36)$ & $42(20)$ & $35(17)$ & $5(2)$ \\
$\quad$ Black men & 237833 & 549563 & 287955 & 667077 & 140941 \\
Black women & 301765 & 694011 & 366065 & 837916 & 168703 \\
White men & 1962058 & 3453562 & 1905333 & 3557046 & 459977 \\
White women & 2166346 & 3797769 & 2136717 & 3971706 & 497700 \\
\hline
\end{tabular}

data were obtained from the 1983 County and City Data Book. ${ }^{27}$

We ranked state economic areas according to the proportion of the civilian labour force employed in white collar occupations, and created five categories of occupational structure by dividing the distribution into five groups-each with an approximately equal range of the distribution. Category 1 is the lowest category of occupational structure (comprised of state economic areas with the lowest percentages of white collar workers) and category 5 is the highest. Equal division of the range of the independent variable allows for rough extrapolation of patterns observed as a categorical variable to patterns expected as a continuous variable.

We computed population weighted average race and sex specific stroke mortality rates for each category of community occupational structure. Patterns of race-sex specific stroke mortality rates and black-white rate differences across the levels of the community occupational structure were assessed. Weighted linear regression was employed to provide summary estimates of the effects of race and community occupational structure on stroke mortality rates, along with the combined effect of race and occupational structure. In the regression model, occupational structure was used as a continuous variable (ie, the percent of white collar workers for each state economic area).

\section{Results}

Descriptive statistics of occupational structure and stroke mortality rates across the state economic areas are presented in table I. Both the mortality rates and the community occupational structure have fairly normal distributions, with black men and black women having distributions of stroke mortality rates skewed slightly to the right. The interdecile ratio shows the largest relative variation in stroke mortality rates among blacks, and indicates a substantial amount of variation in the level of community occupational structure among state economic areas in the south.

The categorisation of state economic areas into levels of occupational structure and the race-sex specific person-years used to calculate the population weighted stroke mortality rates are presented in table II. Although the distribution of state economic areas by occupational structure is skewed toward the left (ie, towards lower levels of occupational structure), the areas in the higher levels of occupational structure have large populations which enhance the stability of the rates.

In the southern region of the US, the 19791981 stroke mortality rates among black men and black women are 2.5 times higher than those of white men and women (rates per 100000 : black men 181 , white men 71 ; black women 128 , white women 52). Within the south, the rates of stroke mortality for both blacks and whites vary by occupational structure, and the magnitude of excess stroke mortality among blacks compared to whites also varies by occupational structure.

Examination of the stroke mortality rates by level of occupational structure (figs 1 and 2) 


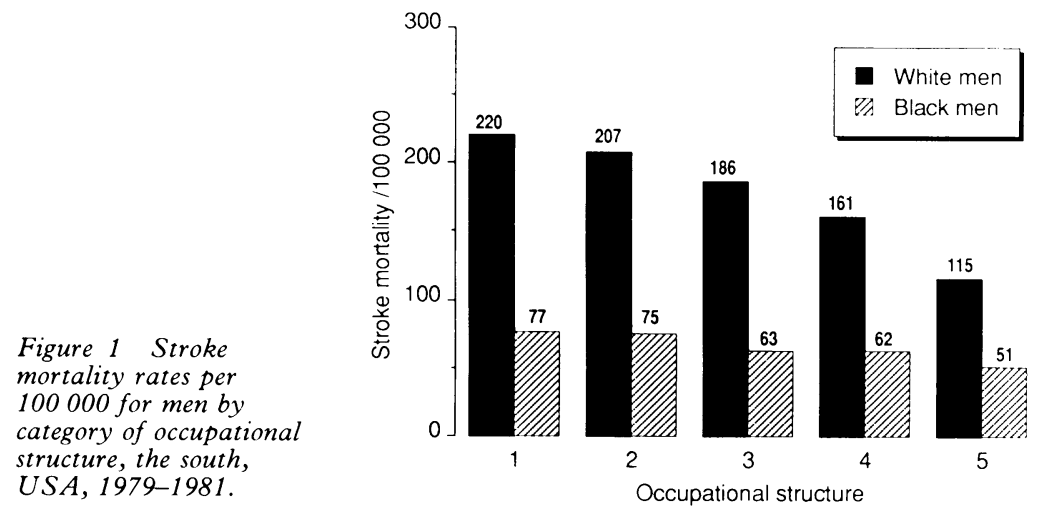

Figure 2 Stroke mortality rates per 100000 for women by category of occupational structure, the south, USA, 1979-1981.
Table III Estimated race and occupational structure effects ${ }^{\mathrm{a}}$ on stroke mortality per 100000 in the south, 1979-1981

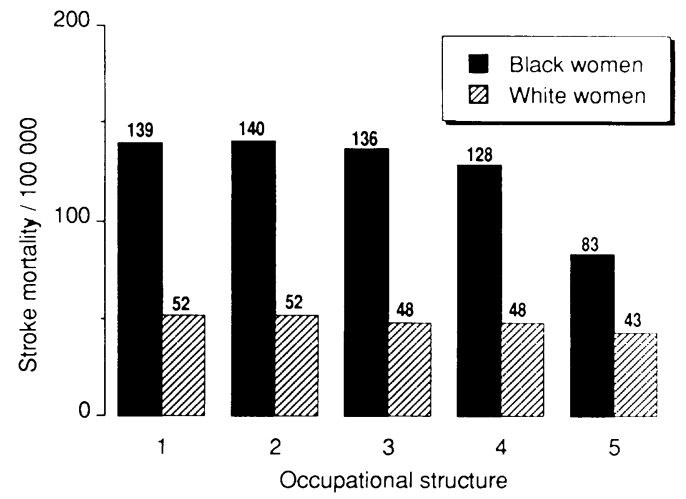

reveals inverse patterns for all four race-sex groups. Stroke mortality rates in low occupational structure communities are higher than rates in the high occupational structure communities. The difference between rates in the lowest and the highest category of occupational structure is larger among blacks than whites, and greater among men than women.

For men, the magnitude of the black-white difference in stroke mortality shows an inverse pattern by level of occupational structure. The

\begin{tabular}{|c|c|c|}
\hline \multirow[b]{2}{*}{ Variable } & \multicolumn{2}{|c|}{ Rate differences } \\
\hline & Women & Men \\
\hline $\begin{array}{l}\text { Race } \\
\text { Occupational structure (blacks) } \\
\text { Occupational structure (whites) }\end{array}$ & $\begin{array}{l}124 \cdot 03 \\
-10 \cdot 6 \\
-0 \cdot 23\end{array}$ & $\begin{array}{r}225 \cdot 40 \\
-29 \cdot 6 \\
-0 \cdot 81\end{array}$ \\
\hline \multicolumn{3}{|c|}{ 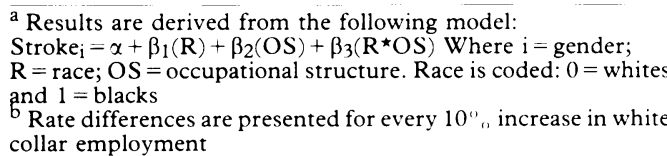 } \\
\hline
\end{tabular}

Table IV Distributions of metropolitan status and 1980 industry profiles ${ }^{\mathrm{a}}$ in the south by category of occupational structure

Occupational structure

1 (low)

2

Metropolitan status
Metro
Non-metro
Industry profile
Agriculture
Manufacturing
Total Services
Health
Education
Other

$4 "$ "
$96^{\prime \prime \prime}$
$8 \cdot 0^{\prime \prime \prime}$
$29 \cdot 8^{\prime \prime \prime}$
$26.9^{\prime \prime \prime}$
$5 \cdot 1^{\prime \prime \prime}$
$7 \cdot 5^{\prime \prime \prime}$
$35 \cdot 3{ }^{\prime \prime \prime}$

$10^{\prime \prime} "$
$90^{\prime \prime}$
$7 \cdot$
$7 \cdot 6^{\prime \prime}$
$21 \cdot 8^{\prime \prime}$
$32 \cdot 2^{\prime \prime \prime}$
$6 \cdot 0^{\prime \prime \prime}$
$8 \cdot 3^{\prime \prime \prime}$
$38 \cdot 4^{\prime \prime \prime}$
3

a Data source: Census of Population and Housing 198
Department of Commerce, Bureau of the Census, 1980 according to metropolitan status

Industry profile = percent of the labour force in each category of occupational structure employed

in a particular industry.
Total services = health services, educational services, business and repair services, finance, insurance and real estate, public administration, other professional and related services, personal, entertainment and recreational services. largest black-white difference in stroke mortality (143 per100 000) occurs in the category of lowest occupational structure. As the level of occupational structure increases from category 2 to category 5 , the black-white differences are 132 , 123, 99, and 64 per 100000 respectively. Among women, the racial difference of stroke mortality appears to be fairly similar among the four lowest categories of occupational structure $(87,88,88$, and 80 per 100000 ) with a sharp decrease in the highest category (40 per 100000 ).

The results from the weighted linear regression analysis, using occupational structure as a continuous variable, are presented in table III. The excess stroke mortality among blacks compared to whites is statistically significant $(\mathrm{p}<0.01)$ for both women $(124.03$ per 100000$)$ and men $(225 \cdot 40$ per 100000$)$.

The effect of occupational structure on stroke mortality is larger among blacks than among whites. For every $10^{\prime \prime} "$ increase in white collar employment the stroke mortality rates among black men and women decrease by 29.6 and 10.6 deaths per 100000 respectively, while the rates among whites decrease by $8 \cdot 1$ and $2 \cdot 3$ deaths per 100000 . These differences in the occupational structure effect on blacks compared to whites are statistically significant $(\mathrm{p}<0.01)$ for both men and women.

The summary estimates of the association between occupational structure, race, and stroke mortality, provided by the weighted linear regression analysis, support the observations from the bar graphs (figs 1 and 2) in which occupational structure was examined as a categorical variable.

\section{Discussion}

In the southern region of the United States, during the years 1979-1981 there was an inverse association between occupational structure and stroke mortality rates for blacks and whites, as well as an inverse association between occupational structure and black-white differentials in stroke mortality. The highest rates and the largest excess mortality for blacks were experienced by communities of lowest occupational structure.

The interpretation of ecological measures as population rather than individual attributes is often ignored despite the logic which links public health concerns to an understanding of properties of the community. Viewed from a public health perspective, the occupational structure of a community reflects the division of labour which is related to economic and political relations with other communities. Communities with lower levels of occupational structure have labour markets which are predominantly blue collar and are based upon manufacturing and/or agriculture activities. As documented in table IV, there is a monotonic association between occupational structure and industry profile. The lower the level of occupational structure, the larger the proportion of the work force which is employed in agriculture and manufacturing. In addition, as the data in table IV indicate, these communities of lower occupational structure are more likely to be non-metropolitan communities. Such 
communities often suffer from economic uncertainty and loss of resources because they are dependent upon the success or failure of a few major employers. ${ }^{28}$ On the other hand, communities of higher occupational structure have labour markets which are primarily service orientated, and are more diversified than the lower occupational structure communities. For instance, in the communities of highest occupational structure $61 \cdot 1{ }^{\circ}$ o of the labour force are employed in services as compared to only $26.9^{\circ}$ o of the labour force in communities of lowest occupational structure. The communities which are primarily service orientated are in a better position to acquire economic stability, and are often the recipients of resources which are derived from the communities of lower occupational structure. ${ }^{2829}$

These social and economic patterns have been documented in the southern region of the USA. Communities of lower occupational structure, which are predominantly rural, have remained underdeveloped, while economic development has occurred in the higher occupational structure urban areas of the south. ${ }^{24}$ Profits from raw materials and cheap labour in the rural south which were previously accrued primarily in the northeast are now being received, to some degree, by areas of higher occupational structure within the south. ${ }^{30}$ Such development has been associated with more stable labour markets and higher levels of well being in the developed areas. However, this sort of development has occurred at the expense of the underdevelopment of the areas that have supplied the basic resources for economic stability, improved working conditions, and improved infrastructure in the developed areas. ${ }^{30-33}$

Our data indicate that the communities with the lowest occupational structure have the highest rates of stroke mortality. These communities are on average less able to provide quality employment, transportation, medical care, education, and housing. Such attributes may influence the distribution of blood pressure levels-the strongest biomedical risk factore for stroke-through nutritional, environmental, occupational, and medical care determinants.

Within the south, underdeveloped low occupational structure areas show not only higher rates of stroke mortality, but also larger racial inequalities in stroke mortality. While excess stroke mortality in blacks compared to whites has been consistently observed in the USA, analyses presented here show that in the south the excess is greater in low than in high occupational structure areas. This suggests that those aspects of the black experience which are conducive to high rates of stroke mortality, including a high prevalence of poor living and working conditions and lack of medical care, are exacerbated in low occupational structure areas of the south. The psychophysiological dimensions of poverty and racism, including suppressed hostility, thwarted aspirations, and raised blood pressure,${ }^{34}$ may be important mechanisms in this process.

At the other end of the spectrum of occupational structure, the black-white differential in stroke mortality is reduced but is still substantial. This would indicate that blacks realise some relative gains in health from living in more affluent communities, but that the distribution and utilisation of wealth serves to maintain social inequalities in health in areas with the most resources. Thus the character of development in areas of high occupational structure remains problematic for the health of black residents as well as for those people living in low occupational structure communities.

The results of this study are subject to biases of outcome misclassification related primarily to the accuracy of medical diagnosis of stroke $\mathrm{s}^{35}$ and choice of underlying cause of death on the death certificate. ${ }^{36} 37$ Accurate diagnosis of stroke is difficult given the diversity of clinical features and the expense of diagnostic tests. The validity of death certificate information is often challenged due to the difficulties and subjective nature of assigning underlying cause of death, and the bias which is introduced by having different people fill out the certificate for each death. It is of interest to note, however, that the results of a national death certificate study suggested that geographical differences in stroke mortality were not due to differences in death certificate coding. ${ }^{38}$ Furthermore, these problems of diagnosis and choice of underlying cause of death are minimised in this study because we excluded the older age groups among whom the difficulties are more serious.

The effects of occupational structure on mortality in the south are not restricted to stroke mortality. A previous study of trends in the association between occupational structure and ischaemic heart disease mortality among whites during the years 1968-1982 reported the emergence of an inverse association in the later years. ${ }^{39}$ After 1972 communities with lower levels of occupational structure experienced higher rates of ischaemic heart disease mortality than communities with higher levels of occupational structure. Furthermore, these findings were strongest for the southern region of the United States.

The results of these studies, and the interpretations we have presented, emphasise the perspective that health experiences of populations are interdependent. Recognising the importance of development patterns and the distribution of resources among social groups such as blacks and whites is crucial to explaining the distribution of disease in populations and planning effective health interventions. More research is needed to gain a better understanding of the mechanisms through which structural characteristics of a community influence the patterns of health and disease within and between communities.

This work was supported by NIH grant No 5-ROIHL42320-01.

1 Lilienfeld AM. Variation in mortality from heart disease: race, sex and socioeconomic status. Public Health Rep 1956; 71: 545-52.

2 Neser WW, Tyroler HA, Cassel JC. Social disorganization and stroke mortality in the black population of North and stroke mortality in the black popula

3 Harburg E, Erfurt JC, Hauenstein LS, Chape C, Schull WJ, Schork MA. Socioecologic stress, suppressed hostility, skin Schork MA. Socioecologic stress, suppressed hostility, skin
color, and Black-White male blood pressure: Detroit. color, and Black-White male b

4 James SA, Kleinbaum D. Socioecologic stress and hypertension related mortality rates in North Carolina. Am f Public Health 1976; 66: 354-8. 
5 Khaw KT, Barrett-Connor E. Dietary potassium and stroke-associated mortality: a population study. N Engl f Med 1987; 316: 235-40.

6 Williams PT, Fortmann SP, Terry RB, et al. Associations of dietary fat, regional adiposity and blood pressure in men. fAMA 1987; 257: 3251-6.

7 McCarron DA, Morris CD, Henry HJ, Stanton JL. Blood presure and nutrient intake in the United States. Science 1984; 224: 1392-8

8 Gill JS, Zezulka AV, Shipley MJ, Gill SK, Beevers DG. Stroke and alcohol consumption. $N$ Engl $\mathcal{F}$ Med 1986; 315 $1041-6$

9 Abbott RD, Yin Y, Reed DM, et al. Risk of stroke in male cigarette smokers. N Engl F Med 1986; 315: 717-20.

10 Karasek R, Baker D, Marxer F, Ahlborn A, Thesrell T. Job decision, job latitude, job demands and cardiovascular disease: a prospective study of Swedish men. Am $\mathcal{F}$ Public Health 1981; 71: 694-705.

11 Cottington EM, Matthews KA, Talbott E, Kuller LH. Occupational stress, suppressed anger and hypertension. Psychosom Med 1986; 48: 249-60.

12 James SA, LaCroix AZ, Kleinbaum DG, Strogatz DS. John Henryism and blood pressure differences among Black men II. The role of occupational stressors. F Behav Med 1984; 7 259-75.

13 Dressler WW. Blood pressure, relative weight and psychosocial resources. Psychosom Med 1983; 45: 527-36.

14 Strogatz DS, James SA. Social support and hypertension Strogatz DS, James Wh. Social support and hy among Blacks and Whites in a rural,

15 Hanson BS, Isacsson SO, Janzon L, Lindell SE. Socia anchorage and blood pressure in elderly men-a population study. F Hypertens 1988; 6: 503-10.

16 Hypertension Detection and Follow-up Cooperative Group Race, education and prevalence of hypertension. $\mathrm{Am}$ Epidemiol 1977; 106: 351-61.

17 Kraus JF, Barhani ND, Franti CE. Socioeconomic status, ethnicity and risk of coronary heart disease. Am 7 Epidemiol 1980; 111: 407-16.

18 Marmot MG, Shipley MJ, Rose G. Inequalities in deathspecific explanations of a general pattern? Lancet 1984; i: 1003-6.

19 James SA, Wagner EH, Strogatz, et al. The Edgecombe County High Blood Pressure Control Program: II. Barriers to the use of medical care among hypertensives. Am F Public Health 1984; 74 : 468-72.

20 Shulman NB, Martinez B, Brogan D, Carr AA, Miles CG. Financial cost as an obstacle to hypertension therapy. $A m \mathcal{F}$ Public Health 1986; 76:1105-8.

21 Keller EB, Brook FH, Goldberg GA. How free care reduce hypertension in the health insurance experiment. $\mathcal{f} A M A$ 1985; 254: 1926-31.

22 Bogue DJ. State economic areas. Washington DC: US Bureau of the Census, 1951.
23 Wing SB, Casper ML, Davis WB, Pellon A, Riggan W, Tyroler HA. Stroke mortality maps: United States Whites aged 35-74 years, 1962-1982. Stroke 1988; 19: 1507-13.

24 Falk WW, Lyson TA. High tech, low tech, no tech: recent industrial and occupational change in the south. Albany, NY: State University of New York Press, 1988.

25 Rosdenfeld S. A divided south. Southern Exposure 1983; 14: 10-17.

26 Rosenfeld S. Bergmar E, Rubin S. After the factories: changing employment patterns in the rural south. Research Triangle Park, N.C.: Southern Growth Policies Board, 1985.

27 County and City Data Book, 9183. A statistical abstract supplement. Washington DC: US Department of Commerce, Bureau of the Census, 1972.

28 Bluestone B. Corporate flight: the causes and consequences of economic dislocation. Washington DC. Progressive Alliance, 1981.

29 Sclar ED. Community economic structure and individual well-being: a look behind the statistics. Int $\mathcal{f}$ Health Serv 1980; 10: 563-79.

30 Fox F. Uneven regional development in the United States. Rev Radical Political Econ 1978; 10: 68-86.

31 Frank AG. The development of underdevelopment. In Frank AG, ed. Latin American: underdevelopment or revolution? New York: Monthly Review Press, 1969.

32 Navarro V. The underdevelopment of health or the health of underdevelopment: an analysis of the distribution of human health resources in Latin America. In: Navarro V, ed. Imperialism, health and medicine. Farmingdale, NY Baywood Publishing Co, 1981.

33 Colclough G. Uneven development and racial composition in the Deep South: 1970-1980. Rural Sociol 1988; 53: $73-86$

34 James SA, Strogatz DS, Wing SB, Ramsey DL. Social economic status, John Henryism and hypertension in Blacks and Whites. Am $\mathcal{F}$ Epidemiol 1987;

35 Ostfeld AM. A review of stroke epidemiology. Epidemiol Rev 1982; 2: 136-52.

36 Gittlesohn A, Royston P. Annotated bibliography of cause of death validation studies 1958-1980. Vital and health statistics, Series 2, No 89. Washington DC: DHHS Publication No (PHS) 82-1363, 1982.

37 Corwin LI, Wolf PA, Kannel WB, McNamara PM. Accuracy of death certification of stroke: The Framingham Study Stroke 1982; 13: 818-21.

38 Kuller $\mathrm{L}$, Anderson $\mathrm{H}$, Peterson $\mathrm{D}$, et al Nationwide cerebrovascular disease morbidity study. Stroke 1970; 1: $86-99$

39 Wing S, Dargent-Molina P, Casper M, Riggan W, Hayes C, Tyroler HA. Changing association between community occupational structure and ischaemic heart disease mortality in the United States. Lancet 1987; ii: 1067-70. 